\title{
Prevalence of Pulmonary Tuberculosis in Unisex Adults at the National Hospital, Abuja, Nigeria
}

Obiora $\mathrm{WC}^{1}$, Ajobiewe $\mathrm{HF}^{1 *}$, Ajobiewe $\mathrm{JO}^{2}$, Ogundeji AA ${ }^{3}$, Umeji LC

${ }^{1}$ Bingham University Karu Nasarawa State of Nigeria

${ }^{2}$ National Hospital Abuja, Plot 132 Garki Central District, Nigeria

${ }^{3}$ United State Department of Defence, Walter Reed Program-Nigeria, US Embassy, Abuja, Nigeria

${ }^{4}$ Defence Reference Laboratory, Asokoro, Abuja, Nigeria

DOI: $10.36347 /$ sjams.2020.v08i06.037

| Received: 01.06.2020 | Accepted: 15.06.2020 | Published: 30.06.2020

*Corresponding author: Ajobiewe H.F

Tuberculosis, though a curable infectious disease, remains one of the leading causes of death in adults. It is also a major public health concern in Nigeria. This study was aimed at determining the prevalence rate of pulmonary tuberculosis in unisex adults at the National Hospital, Abuja. The prevalence of pulmonary tuberculosis in National Hospital was studied using the Gene Xpert MTB/RIF procedure. Gene Xpert MTB/RIF assay technique was used to detect the presence of Mycobacterium tuberculosis. A total of two hundred (200) patients from 18 years and above were screened and enrolled for this study. The study revealed that 13 out of 200 patients were positive with pulmonary tuberculosis with an overall prevalence rate of $6.50 \%$. The most affected age group was between 36-45years having the highest prevalence of infection (15.79\%). Male patients had a higher prevalence at $12.0 \%$, compared to $3.2 \%$ in females. The statistical analysis revealed that there was a significant relationship of prevalence of pulmonary tuberculosis in National Hospital, Abuja with respect to age and gender $(\mathrm{P}<0.05)$. The prevalence rate of pulmonary tuberculosis among Adults in National Hospital, Abuja is slightly above the estimated falling rate of the World Health organization. This means that the prevalence of the infection in National Hospital, Abuja is gradually decreasing and might fall to a prevalence of zero if the necessary measures for preventing spread of infections are put in place.

Keywords: Pulmonary tuberculosis, Gene Xpert, Mycobacterium tuberculosis, Infection.

Copyright @ 2020: This is an open-access article distributed under the terms of the Creative Commons Attribution license which permits unrestricted use, distribution, and reproduction in any medium for non-commercial use (NonCommercial, or CC-BY-NC) provided the original author and source are credited.

\section{INTRODUCTION}

Tuberculosis is the leading cause of death from a curable infectious disease [1]. Globally, more than 1.7 billion people (about 25 percent of the world population) are estimated to be infected with Mycobacterium tuberculosis. The global incidence of TB peaked around 2003 and appears to be declining slowly [2]. Based on results of surveys of the prevalence of infection and disease, and death registrations, an estimated number of 8.9 million new cases of tuberculosis were recorded in 2004 and about 3.9 million cases were sputum-smear positive, the most infectious form of the disease [3]. Tuberculosis (TB) is a chronic infectious disease caused by bacteria generally referred to as Mycobacterium tuberculosis. Almost every organ in the body can be affected, but the lung is the most commonly affected site. Tuberculosis which affects the lungs is called Pulmonary Tuberculosis (PTB) [4]. Tuberculosis spreads through the air. People who are ill with pulmonary tuberculosis are often infectious and can spread the disease by coughing, sneezing or spitting, as these acts propel tiny droplet nuclei containing the tubercles into the air. Inhalation of these tubercles by an uninfected body makes the person infected with tuberculosis but not necessarily sick with the disease. A person ill with pulmonary tuberculosis presents a common symptom which is a cough with sputum production (sometimes with blood)[5]. According to World Health Organization (WHO), tuberculosis happens to be the unprecedented world's most infectious deadly killer with about 4500 lives lost per day [2]. Almost a third of the world's population is infected with tuberculosis germs and is in the risk of tuberculosis. Every year, about 9 million people develop active tuberculosis and 1.5-2 million people die from the disease. More than $90 \%$ of TB cases and deaths occur in developing countries in which $75 \%$ of the cases belong to the economically most active age group i.e. 15 to 54 years old [6]. Nigeria is hit by this global epidemic in Africa and currently ranks $7^{\text {th }}$ in the world and $2^{\text {nd }}$ in Africa among the 30 countries with the highest burden of tuberculosis, TB/HIV, multi drug resistant tuberculosis. 
Significant progress has been made in the fight against tuberculosis, but it continues to be a life-threatening disease that is worsened by many challenges responsible for its prevalence [7]. Despite the use of anti-tuberculosis drugs, pulmonary tuberculosis is still a major health problem and also one of the most important infectious diseases in humans, particularly in developing countries [6]. Pulmonary tuberculosis makes up more than $80 \%$ of TB cases and, is highly contagious in adults with sputum smear-positive. Epidemiologists believe that in $1.2 \%$ of cases, tuberculous infection leads to cavity pulmonary tuberculosis and this mode is highly contagious pulmonary tuberculosis, so each patient can infect an average of 20 people. If people with pulmonary tuberculosis are not diagnosed and treated early, it can result to drug-resistant tuberculosis [3].

Tuberculosis (TB) is a contagious, infectious disease, which usually lasts throughout the life course of a person and determines the formation of tubercles in different parts of the body. Mycobacterium tuberculosis has survived over 70,000 years and it currently infects nearly 2 billion people worldwide[8]; with around 10.4 million new cases of TB each year, almost one third of the world's population are carriers of the TB bacillus and are at risk for developing active diseases[9]. Tuberculosis affects the lungs, though it can also involve other body parts. When it affects the lungs, it is called pulmonary tuberculosis and when it affects other parts of the body such as gastrointestinal system, the musculoskeletal system, the lymphoreticular system, the reproductive system, genitourinary system as well as the skin, bone marrow and the liver (known as miliary tuberculosis), it is called extra pulmonary tuberculosis[10].

Tuberculosis can be categorized as being either active or latent. Latent tuberculosis infection (LTBI), is a state of persistent immune response to stimulation by Mycobacterium tuberculosis antigens without evidence of clinically manifested active tuberculosis. Someone with latent tuberculosis is infected with the tuberculosis bacteria but does not have signs of active TB disease and does not feel ill [11]. However, around 5\% to $10 \%$ of patients with latent infections progress to active tuberculosis disease in the future. The only sign of tuberculosis infection is a positive reaction to the tuberculin skin test or tuberculosis blood test. Latent tuberculosis infection is not infectious and cannot be spread to others [12].

Active tuberculosis, on the other hand, is a condition in which the body's immune system is unable to fight off or defend against the Mycobacterium tuberculosis bacterium. This inability causes an infection of the lungs, which is the most common presentation, or other parts of the body [13]. It is contagious and life-threatening if not properly treated. and causes symptoms which varies depending on whether it is pulmonary or extra pulmonary. General symptoms of active TB include: Unexplained weight loss, Loss of appetite, Fever, Chills, Fatigue and Night sweats.

Mycobacterium tuberculosis is a non-motile, rod-shaped, non-spore forming, obligate aerobe, acidfast bacillus [14]. The rods are 2-4 micrometers in length and 0.2-0.5 um in width. The bacterium is a facultative intracellular parasite, usually of macrophages, and has a slow generation time, 15-20 hours, a physiological characteristic that may contribute to its virulence; this bacillus can withstand weak disinfectants and can survive in a dry state for weeks. MTB is neither Gram-positive nor Gram-negative because it does not have the chemical characteristics of either, although the bacteria do contain peptidoglycan (murein) in their cell wall [15].

Mycobacterium species, are classified as acidfast bacteria due to their impermeability by certain dyes and stains. It is distinguished by its ability to form stable mycolate complexes with aryl methane dyes (carbolfuchsin, auramine, and rhodamine [14]. This is due to an unusual, waxy coating on its cell surface primarily due to the presence of mycolic acid [16], hence once stained, will retain dyes when heated and treated with acidified organic compounds[15]. The cell wall structure of Mycobacterium tuberculosis is unique among prokaryotes, and it is a major determinant of virulence for the bacterium. The cell wall complex contains peptidoglycan, but otherwise it is composed of complex lipids. Over $60 \%$ of the mycobacterial cell wall is lipid. The lipid fraction of Mycobacterium tuberculosis's cell wall consists of three major components, mycolic acids, cord factor, and Wax-D. Mycolic acids are unique alpha-branched lipids found in cell walls of Mycobacterium and Corynebacterium. They make up $50 \%$ of the dry weight of the mycobacterial cell envelope. Mycolic acids are strong hydrophobic molecules that form a lipid shell around the organism and affect permeability properties at the cell surface and are significant determinant of virulence in MTB [16]. They prevent attack of the mycobacteria by cationic proteins, lysozyme, and oxygen radicals in the phagocytic granule. They also protect extracellular mycobacteria from complement deposition in serum. Cord Factor is responsible for serpentine cording. Cord factor is toxic to mammalian cells and is also an inhibitor of PMN migration. It is most abundantly produced in virulent strains of Mycobacterium tuberculosis. Wax-D in the cell envelope is the major component of Freund's complete adjuvant (CFA). The high concentration of lipids in the cell wall of Mycobacterium tuberculosis have been associated with properties of the bacterium includes; impermeability to stains and dyes, resistance to many antibiotics, resistance to killing by acidic and alkaline compounds, resistance to osmotic lysis via complement deposition, 
resistance to lethal oxidations and survival inside of macrophages $[15,16]$.

\section{Pathogenesis of pulmonary tuberculosis}

Infection occurs when a person inhales droplet nucleus containing tubercle bacilli that reach the alveoli of the lungs. These tubercle bacilli are ingested by alveolar macrophages where the majority of these bacilli are destroyed or inhibited[17]. In some individuals, the tubercle subverts the alveolar macrophages' attempt at its degradation and replicates intracellularly for weeks and are released when the macrophages die [14].

If alive, these bacilli may spread by way of lymphatic channels or through the bloodstream to more distant tissues and organs (including areas of the body in which tuberculosis disease is most likely to develop such as the regional lymph nodes, apex of the lung, kidneys, brain, and bone, etc.). This process of dissemination primes and stimulates the immune system for a systemic response[17]. During this time, most patients are asymptomatic and usually have no radiologic evidence of the disease but they develop cellmediated immunity and tests of tuberculosis such as tuberculin test becomes positive. In majority of individuals, pathogenesis ceases at this point and the person becomes asymptomatic and is said to be infected with tuberculosis [14].

\section{Pathophysiology of pulmonary tuberculosis}

The principal mechanism through which pulmonary tuberculosis is contacted is by inhalation of aerosolized droplets from an infected person. Subsequent deposition of the organism in the lungs can lead to a few possible outcomes, including:

I. The immediate clearance of the organism from the body

II. Latent infection

III. Primary disease: The immediate onset of active disease in the individual

IV. Reactivation disease: The onset of active disease many years after a period of latent infection

The body's ability to effectively restrict or eliminate the infective inoculum is dependent on the immune status of the individual, genetics, and primary or secondary exposure to the organism. Mycobacterium tuberculosis also possesses several virulence factors that make its elimination difficult for alveolar macrophages. These factors include the high mycolic acid content found in the bacterium's outer capsule, which makes phagocytosis difficult for alveolar macrophages, the cord factor which can directly damage the alveolar macrophages. Several studies have demonstrated that Mycobacterium tuberculosis also inhibits the formation of an effective phagolysosome, which limits and sometimes even prevents the elimination of the organisms. Other virulence factors include catalase-peroxidase, which helps resist the oxidative response of the host cell, and lipoarabinomannan [18], which helps induce cytokines and resist host oxidative stress [19, 20]. Macrophages in the lungs produce chemokines and cytokines that attract other phagocytic cells, including neutrophils, monocytes, and other alveolar macrophages, which produce a nodular granulomatous structure known as a tubercle.. Also, properties of Mycobacterium tuberculosis that renders it virulent includes: Special mechanisms for cell entry: The tubercle bacillus can bind directly to mannose receptors on macrophages via the cell wall-associated mannosylated glycolipid, or indirectly via certain complement receptors or $\mathrm{Fc}$ receptors. MTB can grow intracellularly. This is an effective means of evading the immune system. In particular, antibodies and complement are ineffective. Once Mycobacterium tuberculosis is phagocytosed, it can inhibit phagosome-lysosome fusion by secretion of a protein that modifies the phagosome membrane. It may remain in the phagosome or escape from the phagosome, in either case, finding a protected environment for growth in the macrophage [15].

Detoxification of oxygen radicals: Mycobacterium tuberculosis interferes with the toxic effects of reactive oxygen intermediates produced in the process of phagocytosis by three mechanisms: Compounds including glycolipids, sulfatides and regulate the oxidative cytotoxic mechanism; macrophage uptake via complement receptors may bypass the activation of a respiratory burst; the oxidative burst may be counteracted by production of catalase and superoxide dismutase enzymes [21].

1. Slow generation time: Because of MTB's slow generation time, the immune system may not readily recognize the bacteria or may not be triggered sufficiently to eliminate them.

2. High lipid concentration in cell wall: This accounts for impermeability and resistance to antimicrobial agents, resistance to killing by acidic and alkaline compounds in both the intracellular and extracellular environment, and resistance to osmotic lysis via complement deposition and attack by lysozyme [15]. Mycobacterium tuberculosis virulence is studied both in tissue culture, mainly using macrophages and more recently dendritic cells [22-24] and pneumocytes [25, 26], and in animal models. While tissue culture models are easier to work with and give faster results, they are limited to the early stages of infection.

\section{METHOD}

The consents of patients were taken before commencing the study. Questionnaires concerning socio-demographic characteristics such as age, educational qualification, occupation, were distributed to the sampled adults. Before processing, the patient's details were entered on the Xpert MTB/Rif worksheet. 
Samples were processed according to manufacturer's instruction.

\section{HYPOTHESES}

\section{RESUlTS}

Table-1: Prevalence of Pulmonary Tuberculosis in relation to Age among adults attending National hospital, Abuja

\begin{tabular}{|l|l|l|l|}
\hline Age & Number Examined & Number Positive & Prevalence (\%) \\
\hline $18-25$ & 49 & 4 & 8.16 \\
\hline $26-35$ & 62 & 2 & 3.22 \\
\hline $36-45$ & 19 & 3 & 15.79 \\
\hline $46-55$ & 43 & 1 & 2.32 \\
\hline Above 55 & 27 & 3 & 11.11 \\
\hline Total & $\mathbf{2 0 0}$ & $\mathbf{1 3}$ & $\mathbf{6 . 5 0}$ \\
\hline
\end{tabular}

$\chi^{2}=10.71, \mathrm{df}=5 ; \mathrm{P}=0.05$

Table-2: Prevalence of Pulmonary Tuberculosis in relation to Sex among adults attending National hospital,

\begin{tabular}{|l|l|l|l|}
\hline Sex & Number Examined & Number Positive & Prevalence (\%) \\
\hline Male & 75 & 9 & 12.0 \\
\hline Female & 125 & 4 & 3.2 \\
\hline Total & $\mathbf{2 0 0}$ & $\mathbf{1 3}$ & $\mathbf{6 . 5}$ \\
\hline
\end{tabular}

$$
\chi^{2}=5.97, \mathrm{df}=1 ; \mathrm{P}=0.015
$$

Table-3: Prevalence of Pulmonary tuberculosis in relation to Marital Status among adults attending National hospital, Abuja

\begin{tabular}{|l|l|l|l|}
\hline Marital Status & Number Examined & Number Positive & Prevalence (\%) \\
\hline Single & 81 & 5 & 6.2 \\
\hline Married & 78 & 7 & 9.0 \\
\hline Widowed/Widower & 33 & 1 & 3.0 \\
\hline Divorced & 8 & 0 & 0.0 \\
\hline Total & $\mathbf{2 0 0}$ & $\mathbf{1 3}$ & $\mathbf{6 . 5}$ \\
\hline
\end{tabular}

Table-4: Prevalence of Pulmonary Tuberculosis based on Ethnicity among adults attending National hospital, Abuja

\begin{tabular}{|l|l|l|l|}
\hline Marital Status & Number Examined & Number Positive & Prevalence (\%) \\
\hline Igbo & 47 & 4 & 8.5 \\
\hline Yoruba & 35 & 3 & 8.6 \\
\hline Hausa & 53 & 2 & 3.8 \\
\hline Others & 65 & 4 & 6.2 \\
\hline Total & $\mathbf{2 0 0}$ & $\mathbf{1 3}$ & $\mathbf{6 . 5}$ \\
\hline
\end{tabular}

$$
\chi^{2}=1.22, \mathrm{df}=3 ; \mathrm{P}=0.75
$$




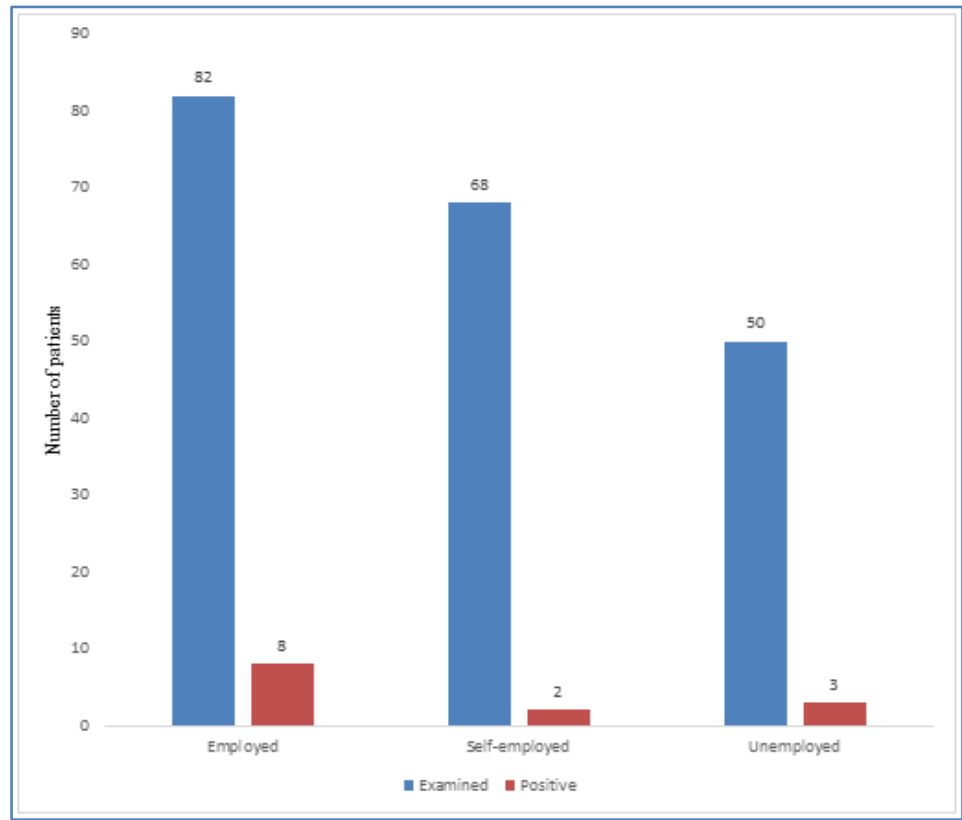

Fig-2: Prevalence of Pulmonary Tuberculosis in relation to Employment among adults attending National hospital, Abuja

Table-5: Prevalence of Pulmonary Tuberculosis in Relation to Educational Status among adults attending National hospital, Abuja

\begin{tabular}{|l|l|l|l|}
\hline Education & Number Examined & Number Positive & Prevalence (\%) \\
\hline None & 1 & 1 & 100.0 \\
\hline Primary & 13 & 0 & 0.00 \\
\hline Secondary & 34 & 0 & 0.00 \\
\hline Tertiary & 149 & 12 & 12.1 \\
\hline Informal & 3 & 0 & 0.0 \\
\hline Total & $\mathbf{2 0 0}$ & $\mathbf{4 3}$ & $\mathbf{2 1 . 5}$ \\
\hline
\end{tabular}

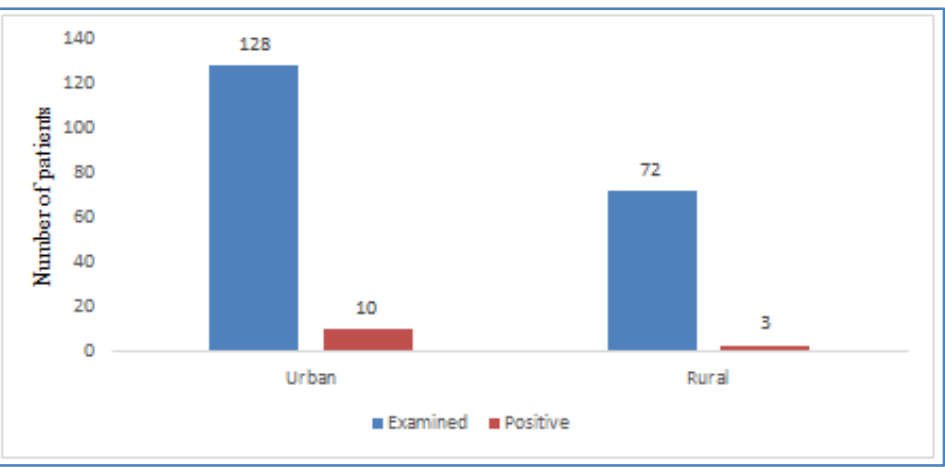

Fig-3: Prevalence of Pulmonary Tuberculosis in relation to Place of Living among adults attending National hospital, Abuja

Table-6: Prevalence of Pulmonary Tuberculosis in relation to Previous Diagnosis of Tuberculosis among adults attending National hospital, Abuja

\begin{tabular}{|l|l|l|l|l|}
\hline Previously Diagnosed & Number Examined & Number Positive & Prevalence (\%) & P-value \\
\hline Yes & 26 & 2 & 7.7 & 0.79 \\
\hline No & 174 & 11 & 6.3 & \\
\hline Number of times diagnosed $(\mathbf{n}=\mathbf{2 6})$ & & & & \\
\hline Once & 4 & 2 & 50.0 & 0.009 \\
\hline Twice & 9 & 0 & 0.0 & \\
\hline Thrice & 13 & 0 & 0.0 & \\
\hline Five times & 1 & 0 & 0.0 & \\
\hline Seven times & 2 & 0 & 0.0 & \\
\hline Total & $\mathbf{2 0 0}$ & $\mathbf{1 3}$ & $\mathbf{6 . 5}$ & \\
\hline
\end{tabular}


Table-7: Prevalence of Pulmonary Tuberculosis in relation to Risk factors of Infection

\begin{tabular}{|l|l|l|l|}
\hline Risk Factor & Total number tested & Number positive (\%) & p-value \\
\hline Smoking & & & \\
\hline Yes & 42 & $1(2.4)$ & \\
\hline No & 158 & $12(7.6)$ & 0.22 \\
\hline Inject Hard Drugs & & & \\
\hline Yes & 28 & $2(7.1)$ & \\
\hline No & 172 & $11(6.4)$ & 0.88 \\
\hline Living with persons with Tuberculosis & & & \\
\hline Yes & 86 & $5(5.8)$ & 0.73 \\
\hline No & 114 & $8(7.0)$ & \\
\hline HIV Status & & & \\
\hline Positive & 45 & $3(6.7)$ & \\
\hline Negative & 155 & $10(6.5)$ & 0.96 \\
\hline Total & $\mathbf{2 0 0}$ & $\mathbf{1 2 ( 6 . 5 )}$ & \\
\hline & & & \\
\hline
\end{tabular}

Table-8: Prevalence of Pulmonary Tuberculosis in relation to Symptoms

\begin{tabular}{|l|l|l|l|}
\hline Symptoms & Total number tested & Number positive (\%) & p-value \\
\hline Chest Pain & & & \\
\hline Yes & 117 & $4(3.4)$ & \\
\hline No & 83 & $9(10.8)$ & 0.03 \\
\hline Cough lasting for 3 weeks & & & \\
\hline Yes & 63 & $3(4.8)$ & \\
\hline No & 137 & $10(7.3)$ & 0.49 \\
\hline Coughing of Blood & & & \\
\hline Yes & 35 & $2(5.7)$ & \\
\hline No & 165 & $11(6.7)$ & 0.84 \\
\hline Fever & & & \\
\hline Yes & 106 & $6(5.7)$ & \\
\hline No & 94 & $7(7.4)$ & 0.61 \\
\hline Loss of Appetite & & & \\
\hline Yes & 120 & $5(4.2)$ & 0.10 \\
\hline No & 80 & $8(10.0)$ & \\
\hline Night Sweat & & & 0.86 \\
\hline Yes & 66 & $4(6.1)$ & \\
\hline No & 134 & $9(6.7)$ & \\
\hline Unexplained weight loss & & & \\
\hline Yes & 89 & $4(4.5)$ & \\
\hline No & 111 & $9(8.10)$ & \\
\hline Total & $\mathbf{2 0 0}$ & $\mathbf{1 2 ( 6 . 5 )}$ & \\
\hline
\end{tabular}

\section{DISCUSSION}

This study revealed an overall prevalence of pulmonary tuberculosis to be $6.50 \%$ among adults in National Hospital, Abuja. This prevalence is lower than a $14.7 \%$ prevalence reported by [27] on their retrospective study on pulmonary tuberculosis prevalence amongst patients attending infectious diseases hospital (IDH) in Kano, Nigeria. It is also lower than a prevalence of $83.3 \%$ amongst patients of Tamale teaching hospital in Tamale reported by [28] and also an overall prevalence of $25.5 \%$ prevalence reported by [29] in Suleja and Minna, Niger State, Nigeria. A prevalence of $6.5 \%$ is however higher than a $3.9 \%$ rate reported by [30] in their study on pulmonary tuberculosis in Pakistan, an estimated prevalence of $1.1 \%$ in the general population of Pakistan [30] and an overall prevalence of $24.8 \%$ reported by [31] in
Calabar. Infection across age groups varied markedly with age group of 36-45years having the highest prevalence of infection (15.79\%). This finding is similar to the report of [27] who reported highest prevalence of pulmonary tuberculosis amongst age group of 3043years. However, in contract to the finding of this study, the study of Imam and Oyeyi was not statistically significant $(\mathrm{P}>0.05)$. However, there was a statistically significant difference between infection rates between ages $(\mathrm{P}<0.05)$. The findings of this study in terms of age also differs from the finding of Sani et al., where age group of 21-30 recorded highest prevalence of infection than other age group. Prevalence of infection with tuberculosis was highest amongst the males of National Hospital Abuja (12.0\%). This was in agreement with the findings of Imam and Oyeyi, who reported higher prevalence amongst male subjects than females. It is also in agreement with the findings of [29] where males 
were also reported to have a higher prevalence of pulmonary tuberculosis in both Minna and Suleja Area of Niger State. High prevalence of pulmonary tuberculosis amongst male as observed in this study might be as a result of the type of activities which males engage in which requires them relating with people of various health status thereby exposing them to tuberculosis.

\section{REFERENCES}

1. World Health Organization. Global Tuberculosis Report; 2004. Retrieved from http://www.who.int/tb/publications/global_report/e $\mathrm{n} /$

2. World Health Organization. Global tuberculosis report. World Health Organization;2018. Retrieved from https://apps.who.int/iris/handle/10665/274453

3. WHO. WHO Global Task Force outlines measures to combat XDR-TB worldwide. Geneva: World Health Organization;2006.

4. Federal Ministry of Health. "Department of Public Health National Tuberculosis and Leprosy Control Programme", Worker's Manuel. 2010. Retrieved from

https://aidsfree.usaid.gov/sites/default/files/tb_niger ia_2010.pdf

5. Pierpaolo de Colombani. Stop TB. Geneva, Europe; 2004. Retrieved July 6, 2007, from http://www.euro.who.int/_data/assets/pdf_file/000 3/68970/fs01E_TBbckground.pdf?ua=1

6. Shahverdi Ehsan \& Khani Allahverdi Maryam. Epidemiology of Pulmonary Tuberculosis. Austin Tuberculosis: Research \& Treatment. 2017; 2(1): 1005.

7. Azizi F, Hatami H, Janghorbani M. Epidemiology and control of common diseases in Iran; 2000: 602616.

8. Wani RL. Tuberculosis 2: Pathophysiology and microbiology of pulmonary tuberculosis. South Sudan Medical Journal; 2012. Retrieved from http://www.southsudanmedicaljournal.com/archive/ february...hysiology-and-microbiology-ofpulmonary-tuberculosis.html

9. World Health Organization. Global Tuberculosis Report 2016. World Health Organization. 2016. Retrieved from http://www.who.int/tb/publications/global_report/e $\mathrm{n} /$

10. Santos-Longhurst A. Types of tuberculosis. Healthline; 2019. Retrieved from https://www.healthline.com/health/types-oftuberculosis\#active-vs-latent

11. World Health Organization. TuberculosisTuberculosis preventive care- Latent tuberculosis infection. World Health Organization. 2019 Retrieved from https://www.who.int > tb > ltbi_faqs

12. CDC. Centre for Disease Control and Prevention; 2014. https://www.cdc.gov/tb/publications/factsheets/gen eral/ltbiandactivetb.htm

13. Jilani TN, Siddiqui AH. Active Tuberculosis. [Updated 2019 Mar 23]. StatPearls Publishing, Treasure Island (FL); 2019. Retrieved from https://www.ncbi.nlm.nih.gov/books/NBK513246/ \#!

14. Cruz A, Starke J. Tuberculosis, In Cherry J, Harrison G, Kaplan S, Steinbach W, Hotez P (ed),Elsevier Saunders. In Feigin and Cherry's textbook of peidatric infectious diseases.2014: 1335-1380. Philadelphia, PA. Retrieved from http://jcm.asm.org/

15. Kenneth Todar. Todar's Online Textbook Of Bacteriology. Madison, Wisconsin; 2012. Retrieved from http://textbookofbacteriology.net/tuberculosis.html

16. Murray PR, Rosenthal KS, Pfaller MA. Medical Microbiology. Elsevier Mosby; 2005.

17. American Thoracic Society and CDC. Diagnostic standards and classification of tuberculosis in adults and children. American Journal of Respiratory and Critical Care Medicine.2000; 161(4): 1376-1395. Retrieved from http://ajrccm.atsjournals.org/cgi/reprint/161/4/1376

18. Lee RE, Li W, Chatterjee D, Lee RE. Rapid structural characterization of the arabinogalactan and lipoarabinomannan in live mycobacterial cells using 2D and 3D HR-MAS NMR: structural changes in the arabinan due to ethambutol treatment and gene mutation are observed. Glycobiology. 2005 Feb 1;15(2):139-51.

19. Githinji, L. N., Gray, D. M., \& Zar, H. J. (2018). Lung function in HIV-infected children and adolescents. Pneumonia, 10(1), 6.

20. Bergot E, Abiteboul D, Andréjak C, Antoun F, Barras E, Blanc FX, Bourgarit A, Charlois-Ou C, Delacourt C, Dirou S, Gerin M. Practice recommendations for the use and interpretation of interferon gamma release assays in the diagnosis of latent and active tuberculosis. Revue des maladies respiratoires. 2018 Oct;35(8):852.

21. Smith I. Mycobacterium tuberculosis pathogenesis and molecular determinants of virulence. Clinical microbiology reviews. 2003 Jul 1;16(3):463-96.

22. Bodnar KA, Serbina NV, Flynn JL. Fate of Mycobacterium tuberculosis within murine dendritic cells. Infection and immunity. $2001 \mathrm{Feb}$ $1 ; 69(2): 800-9$.

23. Hickman SP, Chan J, Salgame P. Mycobacterium tuberculosis induces differential cytokine production from dendritic cells and macrophages with divergent effects on naive $\mathrm{T}$ cell polarization. The Journal of Immunology. 2002 May $1 ; 168(9): 4636-42$.

24. Jiao X, Lo-Man R, Guermonprez P, Fiette L, Dériaud E, Burgaud S, Gicquel B, Winter N, Leclerc C. Dendritic cells are host cells for mycobacteria in vivo that trigger innate and 
acquired immunity. The Journal of Immunology. 2002 Feb 1;168(3):1294-301.

25. Bermudez LE, Goodman J. Mycobacterium tuberculosis invades and replicates within type II alveolar cells. Infection and immunity. $1996 \mathrm{Apr}$ 1;64(4):1400-6.

26. Birkness KA, Deslauriers M, Bartlett JH, White $\mathrm{EH}$, King $\mathrm{CH}$, Quinn FD. An In Vitro Tissue Culture Bilayer Model To Examine Early Events in Mycobacterium tuberculosisInfection. Infection and immunity. 1999 Feb 1;67(2):653-8.

27. Imam TS, Oyeyi TI. A retrospective study of Pulmonary Tuberculosis (PTB) prevalence amongst patients attending infrectious diseases hospital, in Kano, Nigeria. Bayero Journal of Pure and Applied Sciences. 2008:10-5.

28. Audu ES, Gambo MS, Yakubu AA. Rifampicin resistant mycobacterium tuberculosis in Nasarawa
State, Nigeria. Nigerian Journal of Basic and Clinical Sciences. 2017 Jan 1;14(1):21.

29. RA S, Garba SA, Oyeleke SB, Abalaka ME. Prevalence of pulmonary tuberculosis (PTB) in Minna and Suleja Niger state, Nigeria.

30. Cegielski PJ, Kohlmeier L, Cornoni-Huntley J. Relative and Attributable Risks of Tuberculosis due to Undernutrition in a Population-based Sample of Adults. TSRU progress report. 2007.

31. Hirsch-Moverman Y, Howard AA, Frederix K, Lebelo L, Hesseling A, Nachman S, Mantell JE, Lekhela T, Maama LB, El-Sadr WM. The PREVENT study to evaluate the effectiveness and acceptability of a community-based intervention to prevent childhood tuberculosis in Lesotho: study protocol for a cluster randomized controlled trial. Trials. 2017 Dec;18(1):1-1. 